\title{
Revealing lost 16th-century royal emblems on two Andrea Amati's violins using XRF scanning
}

\author{
Marie Radepont ${ }^{1 *}$ (D), Jean-Philippe Échard ${ }^{1,2}$, Matthias Ockermüller ${ }^{1,2}$, Hortense de la Codre $^{1,2}$ \\ and Oulfa Belhadj ${ }^{1}$
}

\begin{abstract}
A key issue in understanding artefacts from the past is the loss of readability of the signs they may have borne. The two 16th-century musical instruments studied here-rare Italian violins made by Andrea Amati (c.1505-1577) in Cremona - bear remains of painted heraldic emblems, which are barely legible and thus remained undeciphered until today. They are exemplary representatives of this research question, indeed combining various types of losses, which are widely encountered on archaeological artefacts: they are now incomplete (parts are missing, surfaces are abraded) and the paint matter itself, of which the signs are made, has altered. In this study, the complete original outlines and geometrical subdivisions of the shields are deduced from calculations based on the conventional heraldic construction practices of the times. Also, in situ elemental imaging of the shield areas-here using scanning X-ray fluorescence (XRF) spectroscopy — brings two types of information: (i) the nature of pigments, allowing to deduce the initial colours of the paints not discernable to the eye, whether abraded or discoloured; (ii) the spatial distribution of these pigments and colours inside the shield. This multi-approach method leads to the unprecedented revelation of a combination of symbols (tinctures of fields, emblematic ornaments, and their relative spatial distribution), all having meanings in heraldic language. The reconstructed coats of arms appear to be pointing to a very specific nine-year period (1559-1568) of the life of the queen Elisabeth (Isabel) of Valois, spouse of Philip II of Spain. We suggest that this approach, combining an imaging spectroscopic technique and a geometrical study of remaining decors, here providing new insights into the musical history at the Court of Spain, may be used to enhance the readability of a wide range of writings, signs and symbols on artefacts from the past.
\end{abstract}

Keywords: Heraldry, X-ray fluorescence, Elemental imaging, Reconstruction, Spanish Court, Andrea Amati

\section{Introduction}

Andrea Amati (c.1505-1577) is the first known maker of musical instruments from the city of Cremona (Italy), then an important city on the Po River, in the duchy of Milan. Only twenty-one instruments, all from the violin family, are attributed to him [1]. This very small group is of outmost importance for the violin history as they

\footnotetext{
*Correspondence: marie.radepont@mnhn.fr

${ }^{1}$ Centre de Recherche sur la Conservation, CNRS-USR3224, Muséum National d'Histoire Naturelle, Ministère de la Culture, 36 rue Geoffroy Saint-Hilaire, Paris 75005, France

Full list of author information is available at the end of the article
}

are the oldest extant artefacts of the world-renowned Cremonese violin-making school, and thus foreshadow the violins by his sons and grandson, and their followers such as Antonio Stradivari (c.1648-1737) or Bartolomeo Giuseppe Guarneri (1698-1744). A very notable feature of the Andrea Amati extant instruments is that most of them (14 out of 21 ) are profusely decorated with paintings and gildings. In particular, heraldic arms, mottos and various emblems can be seen on the back of their sounding boxes, and the motto is usually repeated along the ribs (the sides of the sounding box), painted in gilded capital letters. A first set of nine of these instruments all bear

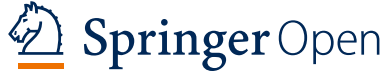

(c) The Author(s) 2020. This article is licensed under a Creative Commons Attribution 4.0 International License, which permits use, sharing adaptation, distribution and reproduction in any medium or format, as long as you give appropriate credit to the original author(s) and the source, provide a link to the Creative Commons licence, and indicate if changes were made. The images or other third party material in this article are included in the article's Creative Commons licence, unless indicated otherwise in a credit line to the material. If material is not included in the article's Creative Commons licence and your intended use is not permitted by statutory regulation or exceeds the permitted use, you will need to obtain permission directly from the copyright holder. To view a copy of this licence, visit http://creativeco mmons.org/licenses/by/4.0/. The Creative Commons Public Domain Dedication waiver (http://creativecommons.org/publicdomain/ zero/1.0/) applies to the data made available in this article, unless otherwise stated in a credit line to the data. 
symbols which are strongly associated with Charles IX, King of France from 1560 to his death in 1574. This set has been regularly discussed in the literature since 1780 [2], and several violin makers and an art historian have recently suggested a link between their decorations and some 16th-century painters active in Cremona or in Fontainebleau $[3,4]$. The other decorated set, counting only five extant instruments (three violins and two tenor violins, none of them bearing an original label, and thus undated), has not been discussed until the 1980s, probably because the painted emblems were less obviously identifiable. Indeed, the common painted elements to these five instruments are a few fleur-de-lis painted in the corners of the back, and the painted motto "QVO VNICO PROPVGNACVLO STAT STABITQVE RELIGIO", probably pointing at a unique commission which is, in the current state of our knowledge, not yet associated to any specific historical figure. However, it is reasonable to assume that the arms painted on these musical instruments are the ones of this person. It was first suggested that this set was "probably [made for] an Italian noble family of marquis rank" [5]. The three violins (inv. NMM 3366, National Music Museum, University of South Dakota, USA; the "ex Kurtz", Metropolitan Museum of Art, New York City, USA; a violin, private collection, Paris, France) exhibit only rare visible remains of paint on their back, probably due to the intense wear to which this arched part is submitted, on the shoulder of generations of musicians, or when placed on tables or sled in their case. Of the two tenor violins, only one (inv. E.1731, musée de la Musique, Paris, France) exhibits on the centre of its back a polychrome heraldic achievement (the decoration on the other instrument, inv. NMM 3370-National Music Museum, University of South Dakota, USA-is not the original one [6]). The coat of arms painted on the tenor of the musée de la Musique is extremely interesting, because the extent of remaining polychromy allows to attempt reading its heraldic visual design. Dominique Morché identified the half side on the left of the shield to the arms of the Spanish Royal family-possibly Philip II, King of Spain from 1556 to 1598-[7]. The hypothesis was drawn that the "Qvo VNICO..." set was commissioned by-or presented to-Philip II [8]. Though, the princely style of the crown on top of the shield, whereas Philip II was King from 1556 on, led to contest this attribution [9]. A reconstruction of the full shield was proposed, where the right side would be repeating heraldic patterns of the left side [10]. It is also true that the right side of the shield of this instrument, exhibiting today an almost even brown/beige paint layer, has remained undiscussed, solely leading to suspect overpaints or other anthropic modifications of this part of the shield. However, it shall first be pointed that the heraldic representations identified on the left side may not only correspond to Philip II King of Spain, but also to his father Charles V, Holy Roman Emperor (1500-1558), his son Philip III or his grandson Philip IV of Spain, as well as to several other members of the Habsburg family. They are thus not univocally identifying a single member of this family. Second, the difficult readability of the right side does not seem a sufficient reason to overlook its contribution in the heraldic representation. Observations under ultraviolet light were reportedly not improving the readability of this part [8]. Further investigation is required to bring new insights to this question, which would be useful to (i) univocally identify a historical character associated to these instruments, (ii) possibly suggest the dating of the paintings and, as a consequence, (iii) possibly suggest the terminus ante quem dating for the instruments.

$\mathrm{X}$-ray fluorescence (XRF) analyses are nowadays currently performed in the cultural heritage domain, especially due to their non-destructive and non-invasive capabilities. The possibility of visualizing the distribution next to the identification of materials present renders XRF scanning particularly interesting for the study of paintings $[11,12]$. Moreover, the penetration of X-rays in matter offers great results for visualizing hidden layers of paintings [13], especially when the chemical elements present below the surface are heavier than the ones in the upper layer. And in some cases, XRF scanning has proved its efficiency in identifying lost pigments such as antique polychromy on a stone bas-relief [14].

The present study explores further the use of XRF scanning to improve the legibility of heraldic patterns and the readability of coat of arms which are now undecipherable on historical artefacts. XRF scanning was performed on two instruments of the "QVO VNICO..." set of instruments made by Andrea Amati. This analytical technique, coupling very high sensitivity (traces levels) and imaging features (spatial distribution, sub-millimetric resolution, large surface), was used here to reveal the initial design of the painter(s) to represent heraldic shields despite a very heavy abrasion of the paintings, modifications of the instruments, and strong alterations in pigments chemistry and thus the colours of the paints.

\section{Materials and methods \\ Studied musical instruments}

The central shield of two of the five instruments of the "Qvo VNICO..." set by Andrea Amati were studied. The first instrument (inv. E.1731, musée de la Musique, Fig. 1a) is an undated tenor violin, which was later transformed to a viola-a smaller instrument-probably in the 18th century (current body length: $395.4 \mathrm{~mm}$ ). Its provenance and history are known from the early 19 th century [15]. The current unbalanced and truncated appearance 


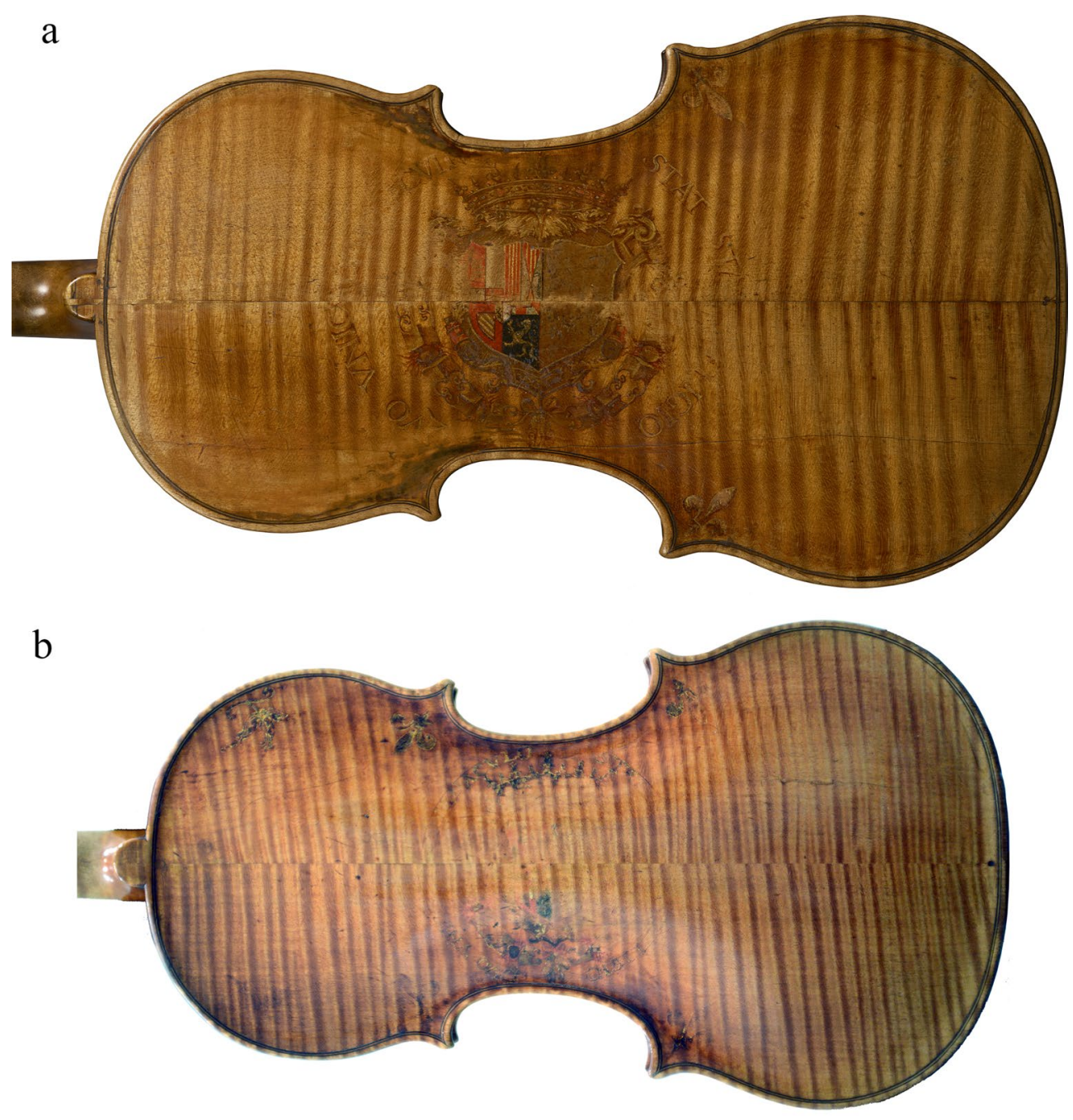

Fig. 1 Photographs of the backs of $\mathbf{a}$ the tenor violin (later cut-down to a viola) inv. E.1731 and $\mathbf{b}$ the violin (private collection) studied. Photos by $\mathbf{a}$ Jan Röhrmann and $\mathbf{b}$ Jean-Philippe Échard, both @ Cité de la musique-Philharmonie de Paris

of the painted shield is the consequence of the removal of a wood strip along the central axis of the back, which was a part of the process to reduce the size of the instrument (Fig. 1a). The missing wood strip was previously assessed to be $2 \mathrm{~cm}$ wide [10]. The second instrument studied is an undated violin (body length: $353.9 \mathrm{~mm}$ ) today in a private collection (Fig. 1b) [16]. Only a few remains of red and dark paints, corresponding to the bottom-left part of the shield of a coat of arms, are visible to the naked eye on the wood surface of the violin back.

\section{Geometrical reconstruction of the shields}

The outlines and dimensions of the shields on the two instruments are incomplete for two different reasons; the reconstruction methods are thus specific to each shield.
On the cut-down tenor, the geometrical reconstruction was performed from a photograph, which had firstly been scaled to natural size and homographically re-mapped for out-of-plane misalignments of the camera. The length of the back, the maximal widths of its upper and lower bouts, as well as the minimal width of its middle bout (all of which have been determined by repetitive measuring with a caliper in triplets) were used as reference value. The scaled photograph and the reference values correspond to each other within $\pm 0.1 \mathrm{~mm}$. We reconstructed the initial relative positions of the two halves of the shield, assuming that it had been subdivided into rectangular subfields after heraldic conventions. After determining the mean lengths of the sides of the rectangular subfields from the best-preserved subdivisions of 
the shield, a possible positioning of the two halves that would match at best the pattern of the shield is discussed. Then, a reconstruction of the original outline and dimensions of the shield is proposed. Concerning the shield on the violin, it is abraded to the point that its outline is largely unreadable under white light. The geometrical reconstruction was performed from a photograph under UV-rich illumination, which creates a chemical contrast highlighting parts of the outline.

\section{UV-light observation and photography}

UV-induced visible fluorescence observations were performed using a Philips "black light" (rich in UV light) neon tube. Figure $4 \mathrm{e}$ was produced using Nikon D600 full-frame digital camera with a AF 28-85 $\mathrm{mm} \mathrm{f} / 3.5-4.5$ Nikkor objective at $85 \mathrm{~mm}, 15 \mathrm{~s}$ exposure time, f.13, ISO 2000.

\section{Light microscopy}

Observations of the paint materials were carried out using in situ microscope (Axio Scope.A1, Zeiss) equipped with Epiplan objectives (5x/0.13 HD, 10x/0.20 HD, $20 \mathrm{x} / 0.4 \mathrm{LD}, 50 \mathrm{x} / 0.50 \mathrm{HD})$, a polarizer and a rotating analyzer. Images were acquired using a Leica DFC 320 camera.

\section{Elemental imaging of the paintings}

X-ray fluorescence scans were performed with the M6 Jetstream instrument (Bruker) [17] equipped with an $\mathrm{X}$-ray tube with a rhodium anode at $50 \mathrm{kV}$ and $600 \mu \mathrm{A}$ with a $100 \mu \mathrm{m}$-thick beryllium window. Polycapillary optics were used to focus the X-ray beam. The X-ray detector was a $60 \mathrm{~mm}^{2} \mathrm{SDD}$ with a Peltier cooler, which 4096 channels were divided into $40 \mathrm{keV}$ with a maximum count rate of $275 \mathrm{kcps}$. The target was placed horizontally at a working distance of $1.5 \mathrm{~cm}$. The beam presented a diameter of $180 \mu \mathrm{m}$, the distance between each point was $180 \mu \mathrm{m}$ and the time per point $200 \mathrm{~ms}$. Data were processed with the Esprit program developed by Bruker.

On each instrument, two acquisitions were performed: one on the upper part of the shield and one on its lower part. For each acquisition, the instrument was tilted so that the average plane of the arched surface is perpendicular to the X-ray excitation beam.

\section{Results and discussion}

In the following are presented and discussed the results dealing with the materiality of the painted images and their potential to retrieve the original intended representation of these painted symbols. This will be considered as independent from the nature of the painted objects, that is, here, musical instruments.

\section{Pigments identification on the tenor shield}

Multiple chemical elements were detected by the XRF analyses of the painted shield on the tenor, allowing the identification of pigments from their elemental composition signatures and the appearance of the painted areas. In situ microscopic observations of the paints allowed refining pigments determination. The painter's palette was thus characterized and the possible corresponding heraldic tinctures were deduced.

Microscopic observations of the different yellow-coloured areas still visible today on the shield as well as on the surrounding decorative elements show the presence of golden particles applied as brush strokes in a transparent medium (see Additional file 1: Figure S1). The distribution of gold-the chemical element-given by XRF scanning mostly corresponds to these areas, such as the thin outline of the shield, the vertical and diagonal stripes on the upper and lower-left parts respectively, a trapezoidal shape and a quadruped animal figure (Fig. 2). Additionally, on the right side, some pixels showed the presence of gold in very small areas barely visible to the naked eye, probably traces of pictorial elements made from this material (See Reconstruction and interpretation of the heraldic representation).

The distribution of mercury mostly corresponds to red areas still visible on the shield (Fig. 2). The presence of this element, co-localized with sulfur, led to attributing this colour to vermilion, a bright red pigment made of mercury sulfide [18]. This paint was used as background for red areas of the shield, as well as for highlighted details. The distribution of mercury also shows the presence of this pigment in some thin straight strokes, corresponding to limits of shield subdivisions. Only a part of these lines is visible to the eye, while subsequent paint layers cover the remaining part. These lines thus might be interpreted as an underpainting to elaborate the shield design.

Another element detected by XRF in the coat of arms was iron, co-localized with manganese (Fig. 2) in the background of the area with the animal figure and all around the shield. These elements might indicate the use of a natural earth pigment such as umber [19]. Such a material though would not fully explain, alone, the black colour in the background of the animal figure. Going further would require sampling material and using a set of micro-invasive analytical techniques.

Concerning the white areas, lead was detected by XRF analyses on several geometrical areas on the upper and lower parts of the shield (Fig. 2), which is consistent with the use of the lead white pigment [20]. 


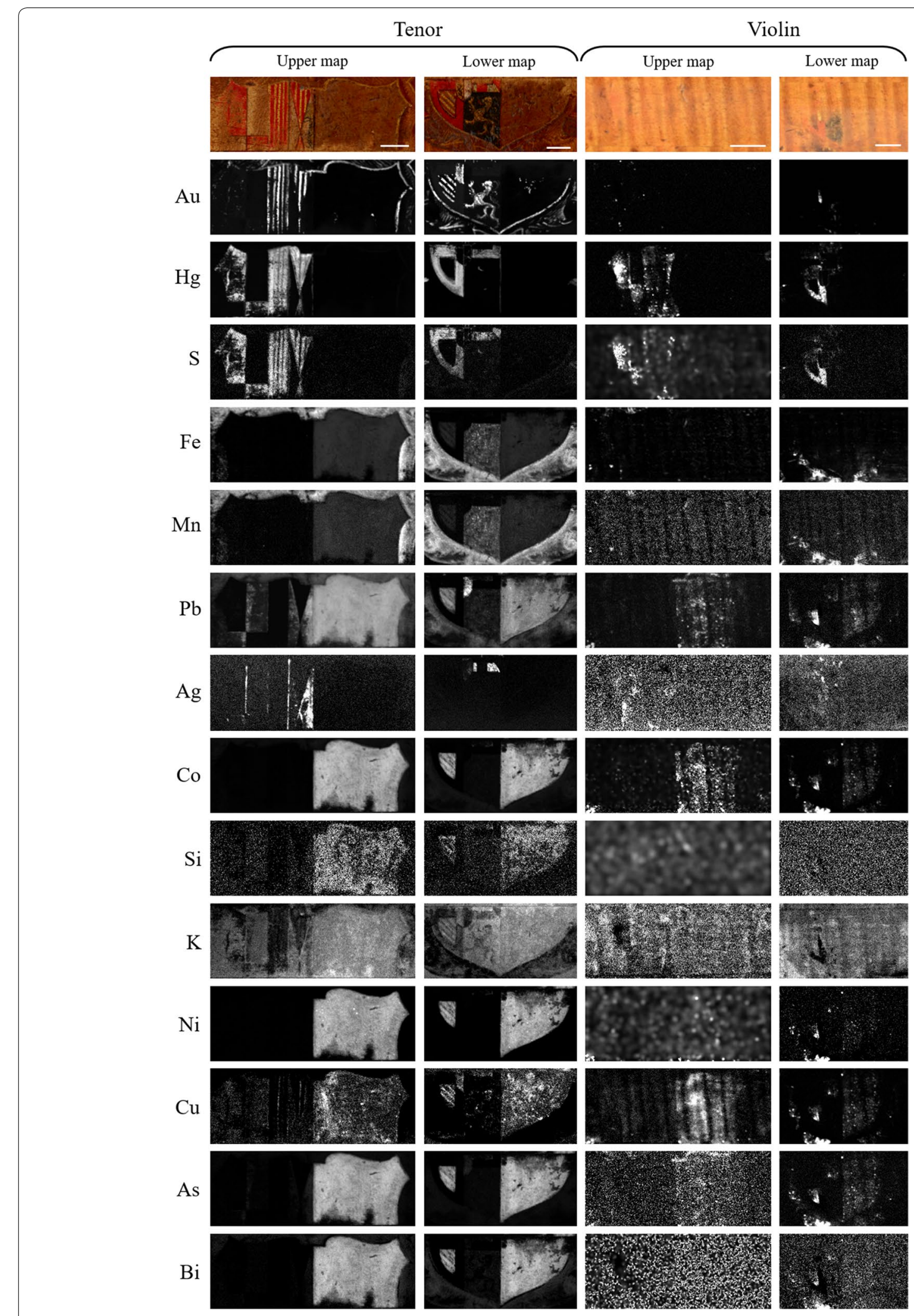

Fig. 2 Photographs of the upper and lower parts of the tenor and the violin (scale bars: $10 \mathrm{~mm}$ ) and the corresponding elemental XRF scans showing in white scale the distribution of $\mathrm{Au}-\mathrm{La}$, $\mathrm{Hg}-\mathrm{La}$, S-Ka, Fe-Ka, Mn-Ka, Pb-La, Ag-La, Co-Ka, Si-Ka, K-Ka, Ni-Ka, Cu-Ka, As-Ka and Bi-La 

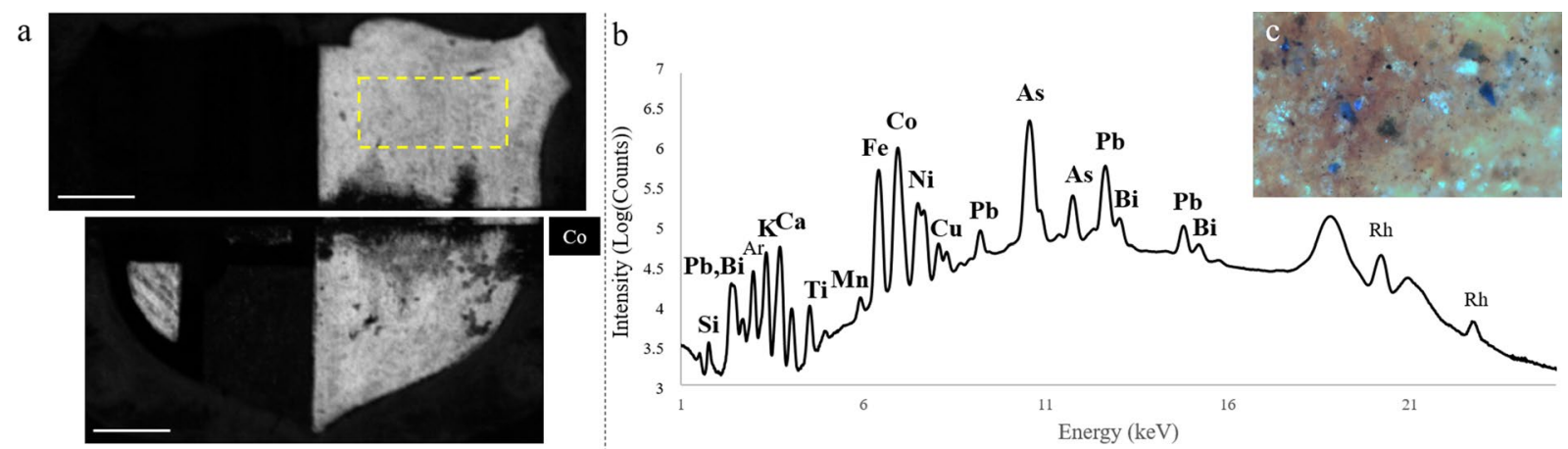

Fig. 3 a Elemental XRF scans showing in white scale the distribution of Co-Ka on the coat of arms of the tenor (scale bars: 10 mm); the dashed yellow rectangle localizes the 5488 acquisition spectra summed in (b); c Microscopic bright-field crossed polars image of blue grains of pigment taken on the right side of the shield (field of view: $500 \times 300 \mu \mathrm{m}$ )

Traces of silver were detected, especially on two small polygonal areas in the lower part and on multiple areas in the upper part (Fig. 2). On silvered areas, microscopic observations showed that the flakes are shiny but partially black, which could be explained by the corrosion of silver [21]. The similar distribution of silver and lead in these areas might be due to the use of lead white paint as a ground for silver leaves [22], except from the polygons on the lower part where the leaves were affixed on vermilion.

The elemental scan also showed the presence of cobalt (Figs. 2 and 3a). This element was mainly present in the right half and in the bottom left of the shield, co-localized with a paint material showing a brownish/beige aspect to the naked eye. Together with cobalt, silicon, potassium, nickel, arsenic and bismuth are also detected (Figs. 2 and $3 \mathrm{~b}$ ). All these elements together, and co-localized, are consistent with the use of smalt, and considered as elemental fingerprinting of this glassy blue pigment [23, $24]$. Widely used between the 15th and the 18th centuries, smalt is also well known for its tendency to fade over time $[25,26]$. Microscopic examination of the painting materials evidenced, among a vast majority of whitish transparent particles, a few blue particles whose shapes (including conchoidal fractures) are characteristic of a glassy material (Fig. 3c).

Potassium is detected in areas larger than the cobaltcontaining ones (Fig. 2). This might be due to the presence of this chemical element in woods, regularly detected in this material, and notably reported to be present in violin woods [27]. In the elemental scans, the contrasts observed for the potassium distribution might then be due to the presence of different chemical elements on top of the wood, with a strong absorption of the fluorescence emitted by potassium when mercury or gold is present at the surface.

\section{Pigments identification on the violin}

The pigments detected on the tenor and detailed above were also identified on the violin by XRF analyses. Whereas it was possible, on the tenor, to be guided by the visible colours of many of the painted areas, on the violin however, only chemical scans could help determining the materials used to paint the coat of arms, nowadays lost by abrasion or by the loss of bonding (Fig. 1).

The distribution of gold on the violin corresponds to areas where gold is also detected on the tenor, even if its concentration was much lower, making the elemental scans less clear (Fig. 2). Similarly, silver was hardly detected on the violin (Fig. 2). In fact on the tenor, we observed that gold and silver were mainly painted over other paint layers. These more superficial layers were certainly the first affected by the extended abrasion and wear the violin has suffered. Despite this alteration of the violin's surface, elemental scans show the presence of the same main elements as on the tenor, with weaker signals but at locations in the shield where they are also present in the tenor (Fig. 2). This certainly is attributable to the fewer pigment particles still adhering to the wood surface, notably in its interstices.

\section{Geometrical reconstruction of the shields}

On the tenor, a central wooden strip was removed from the back plate along the axis of the instrument (see "Materials and methods" Studied musical instruments), leaving only the upper and lower parts of the shield extant. Still, many straight lines are visible on the left side of the shield. They correspond to the initial design to subdivide the left side into multiple heraldic subfields. It is here assumed that this design was created following conventional heraldic rules, and in particular that the subdivisions are uniformly distributed, on both the vertical axis and the horizontal one. The subdivision pattern 

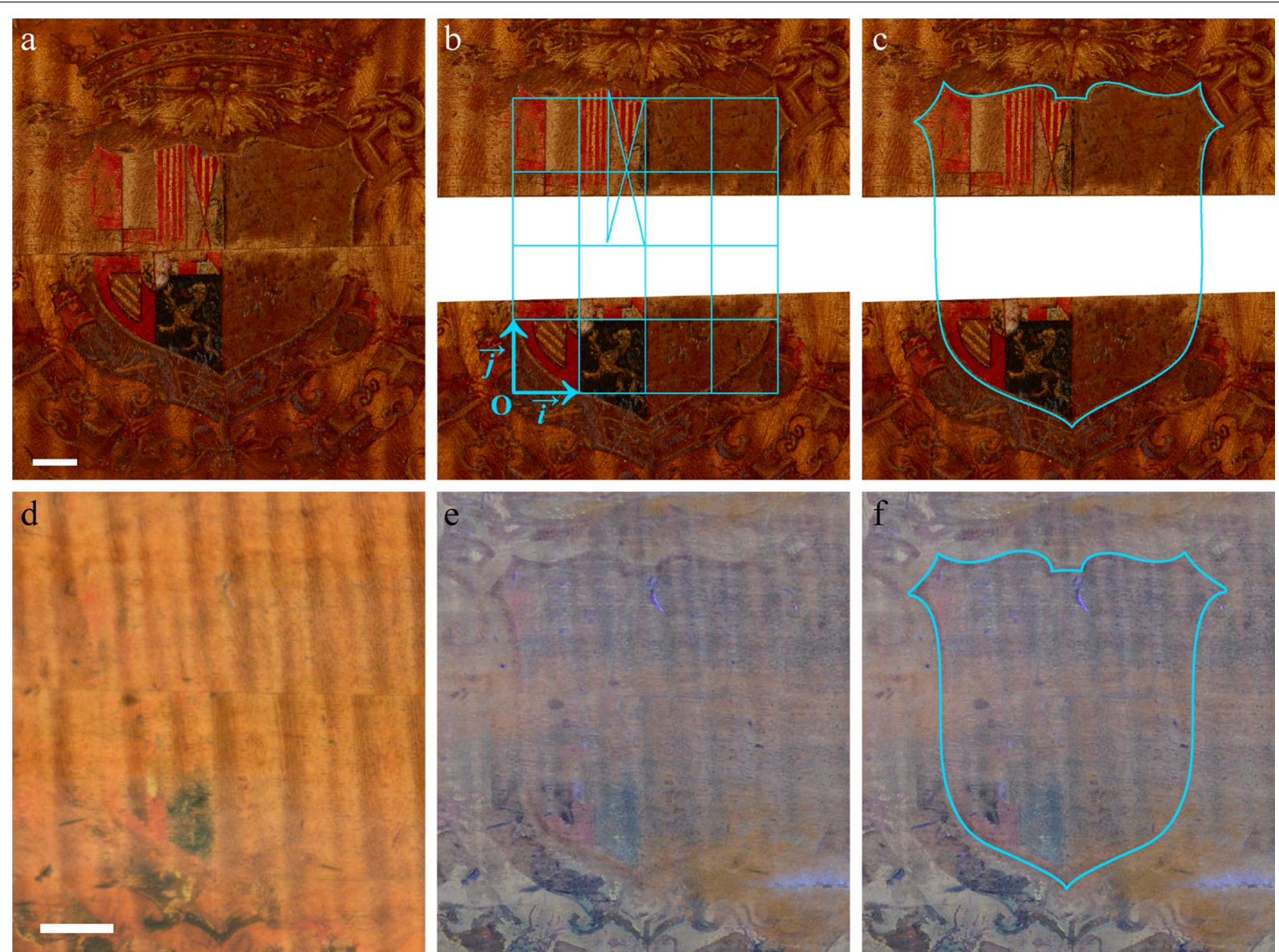

Fig. 4 Reconstruction of the original outlines of the shields on the tenor $(\mathbf{a}-\mathbf{c})$ and on the violin $(\mathbf{d}-\mathbf{f})$. a Photography under white light of the tenor shield in its current state; $\mathbf{b}$ Estimated original positions of the two halves of the tenor shield positioned on the orthogonal coordinate system used for the reconstruction; $\mathbf{c}$ Reconstructed shield outline on the tenor; $\mathbf{d}$ Photography under white light of the violin shield; e Photography of the violin under UV-rich light; $\mathbf{f}$ Reconstructed shield outline on the violin (scale bars: $10 \mathrm{~mm}$ )

should thus correspond to a rectangular tiling. Horizontal and vertical segments-which could correspond to unit, fractions or multiples of the sides of such a unit rectangle-were identified and measured (see Additional file 1: Figure S2 and Tables S2 and S3). The mean horizontal and vertical side lengths were thus calculated to 15.0 and $16.6 \mathrm{~mm}$, respectively.

A 2D orthogonal coordinate system was defined using these values as the unit of lengths, tiling the plane with unit rectangles (Fig. 4b). The central axes of the top and bottom halves of the shield were both aligned on the line defined by $x=2$, inducing a relative rotation of $0.55^{\circ}$ between the two halves. The relative vertical translation of the two halves was then performed in order to (i) satisfy the alignment of many construction lines of the shield on the tiling and (ii) give the shield a height:width ratio better corresponding to usual coat of arms representations (Fig. 4b). The original shield design appears to be based on a $4 \times 4$ grid. Interestingly, it can be remarked that not only the two diagonal construction lines visible in the upper-left area of the shield intersect very closely to a remarkable point of the grid $\{1.75 ; 3\}$, but also each of these diagonal lines ends in the vicinity of other remarkable points $\{1.5 ; 4\},\{2 ; 2\},\{1.5 ; 2\},\{2 ; 4\}$. These observations reinforce the plausibility of the repositioning method. It is thus possible to reconstruct the most probable outline of the shield as it had been created originally (before the instrument was cut-down) (Fig. 4c). As a side result, the width of the cut-down wooden part can be determined: $23,5 \mathrm{~mm}$ on the left side and $22,4 \mathrm{~mm}$ on the right side.

On the violin, the geometrical reconstruction of the shield outline and dimensions from the photography under UV-rich illumination is more straightforward. The shield outline is revealed under UV-rich illumination (Fig. 4e, f).

The two shields present the same elaborated design, notably in the upper part, of a design not so common in heraldic representations. Painted on instruments 

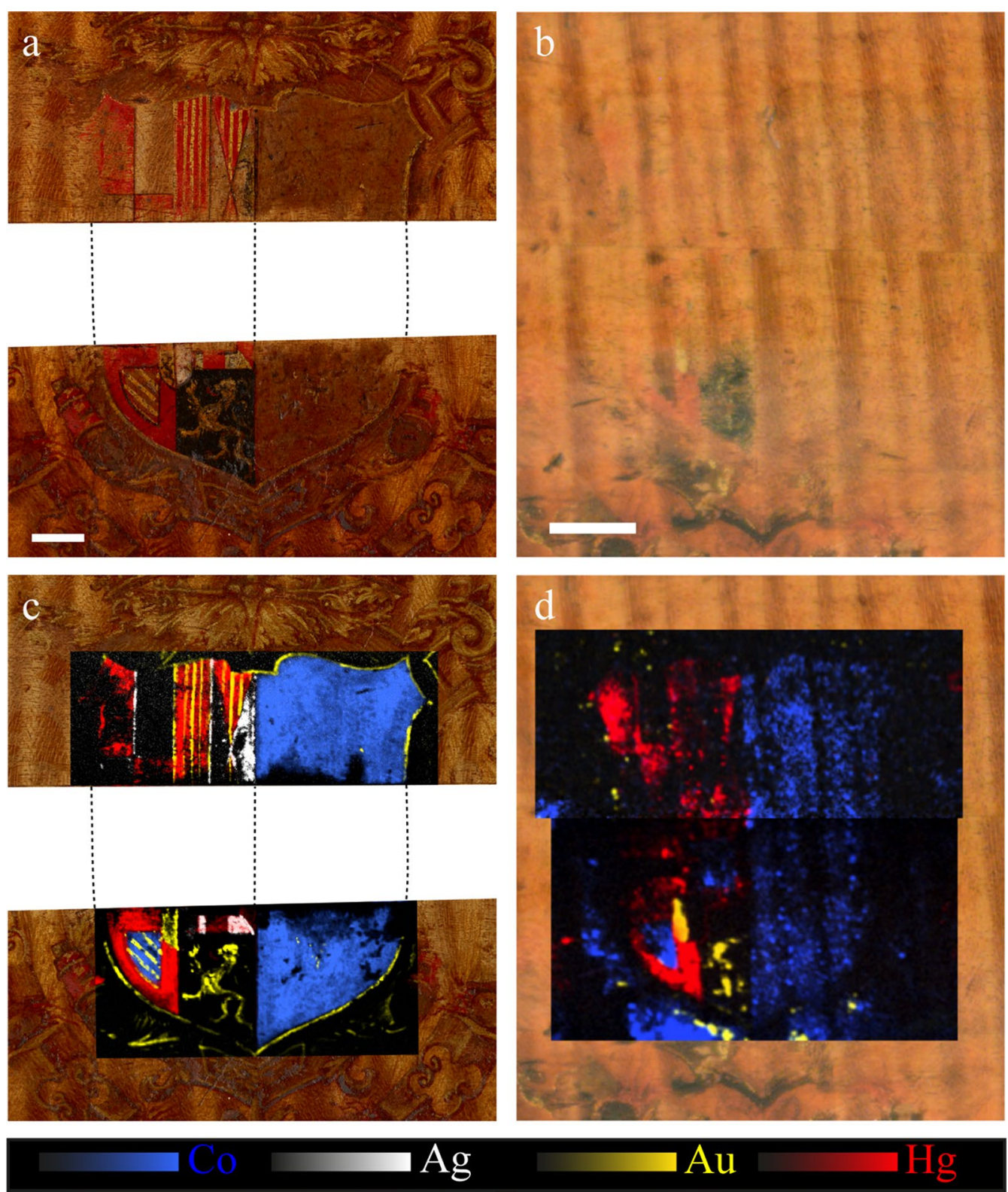

Fig. 5 Photographs (scale bars: $10 \mathrm{~mm}$ ) and elemental scans obtained by XRF spectroscopy on the coats of arms of the tenor (a and $\mathbf{c}$ ) and the violin (b and $\mathbf{d}$ ), showing the distribution of Co-Ka (blue), Ag-La (white), Au-La (yellow) and Hg-La (red)

of different sizes, they are understandingly not of the same dimensions, but present similar height/width ratios (1.11:1 and 1.06:1 for the tenor and the violin, respectively).

\section{Reconstruction and interpretation of the heraldic representation}

Most of the pigments identified by XRF analyses were consistent with the visible colours on the decorations of the two instruments. Indeed, most of the red areas correspond to the presence of vermilion, white ones to the presence of lead white and silver, bright ones to the use of gold, dark-brownish ones to the presence of earth pigments, and brown-beige to the presence of degraded smalt (Fig. 5).

It appears that the arms painted on both instruments show (i) similar elemental pigment signatures and (ii) very coherent pigment distributions. More precisely, the pigments distribution in the arms of both instruments 
seem to correspond to the same geometrical set-up: knowing that these paints are representing heraldic arms, we can indeed read the spatial distribution of the lines subdividing the shields. Notably, the four elements presented in Fig. 5c, d are particularly well supporting such a conjecture. In particular, there appears to be an important chemical contrast between the left and right sides of a central vertical axis: whereas cobalt is present (together with the other smalt-related elements) in the right side of both arms, indicating that this entire half was painted in blue, the left side of this central axis appears to be subdivided in many subfields. On the upper part of the left side of the shields, both distributions for mercury suggest a field's subdivision using several straight lines (vertical, horizontal and diagonal). The same approach can be used to the lower left part of the shield. Among others, a vertical subdivision as well as a little shield are present in the middle of this area in both instruments. The complete reading of the subdividing lines evidenced in each instrument is represented in Fig. 6a, evidencing the similarity between the set-ups of both painted arms.

Interestingly, the violin shield has not been truncated and brings up information that is missing from the cutdown central part of the tenor shield. These two paintings certainly depict the same arms, and complement each other in order to reconstruct it. A thorough in-depth research into known heraldic rules and catalogued coat of arms of historical figures, led to define the set of arms shown on Fig. $6 \mathrm{c}$ as the most probable one.

Even if similar shields seemed to be painted on the tenor and the violin, it cannot be certified that the same painter decorated these musical instruments. Other elements from the decors would have to be precisely observed and compared to further study the pictorial technique(s) used. In the following, the correspondence between the painted fields on the instrument and the heraldic description (in italic in parentheses) of European regions is proposed (see Fig. 6b for areas numbering). The mercury- and silver-containing rectangular backgrounds in the field (I) are in accordance with the heraldic description of Castile and Leon (1 and 4 gules a three towered castle Or masoned sable and ajouré azure, 2 and 3 argent a lion rampant purpure crowned Or langued and armed gules).

In the field (II), the distribution of mercury-containing red fields, gold-containing stripes, silver- and lead-containing fields with traces of iron-rich black lines are in accordance with the heraldic description of Aragon on the left (dexter) side and Aragon-Sicily on the right (sinister) side (per pale, (i) dexter per fess, Or four pallets gules and (ii) sinister per saltire, 1 and 4 Or four pallets gules, 2 and 3 argent an eagle displayed sable). a

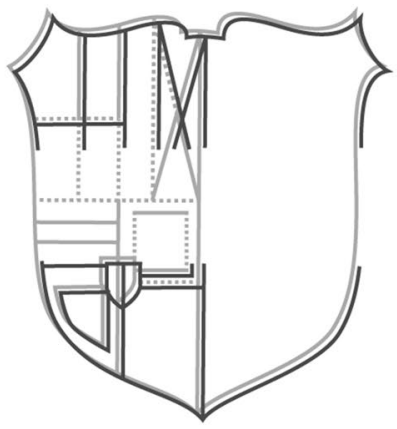

b

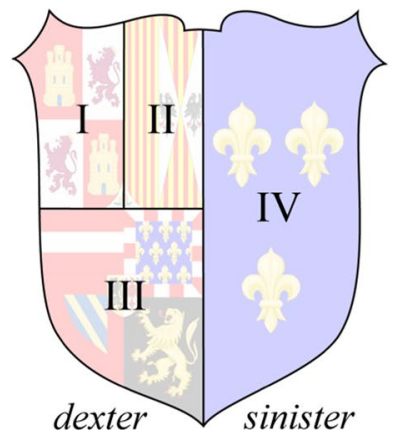

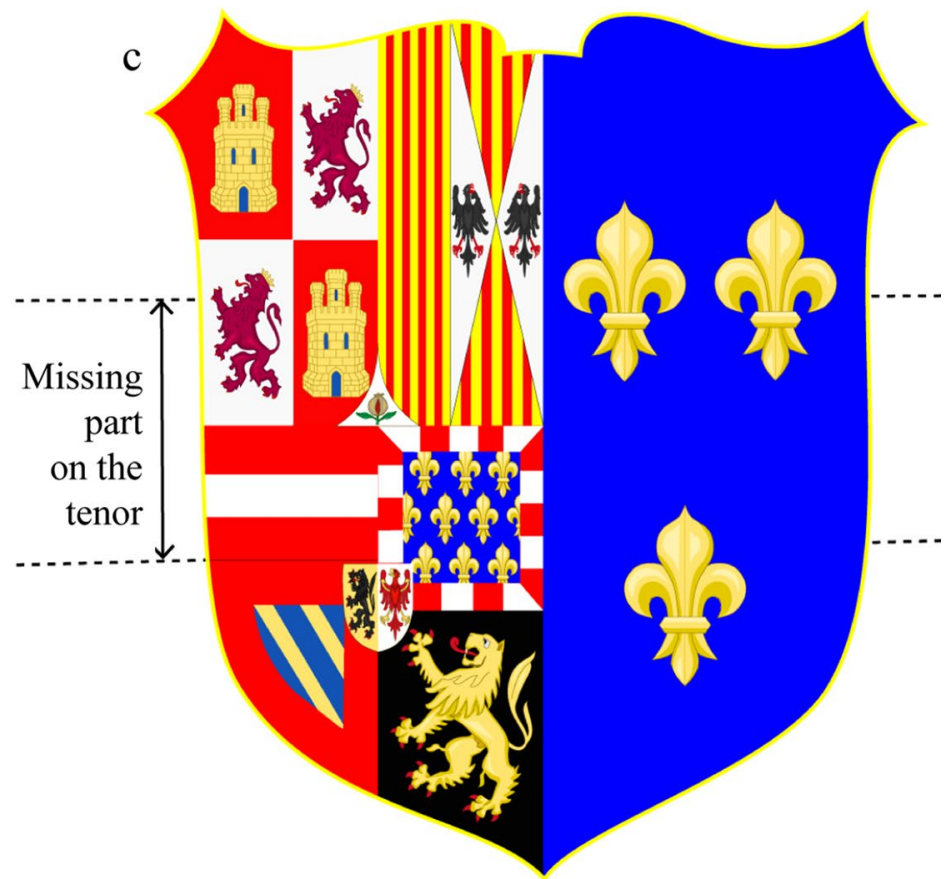

Fig. 6 a Reading of the subdividing lines evidenced in the set-up of the arms on the violin (grey lines) and on the tenor (black lines), presented with a shift in order to ease the comparison; $\mathbf{b}$ Numbering of areas for the description of the coat of arms; $\mathbf{c}$ Proposed schematic reconstruction of the shields painted on the back of the two instruments 
The bottom-left quarter of the shield (field (III)) appears to be divided in 4 quarters with an inescutcheon overall at the center. In the top-left quarter of field (III), the two mercury-rich red bands are in accordance with the heraldic description of Austria (gules a fess argent). The topright quarter, with a mercury-rich red border, highlighted with silver squarish areas, and traces of smalt pigment in the center, is in accordance with the heraldic description of new Burgundy (azure semy-de-lis Or a bordure compony argent and gules). The bottom-left quarter, with a mercury-rich red border around a smalt-containing field diagonally-striped with thin gold-containing lines, clearly is a representation of old Burgundy (bendy of six Or and azure a bordure gules) whereas the bottom-right one, where a tailed quadruped animal figure is painted in gold, with vermilion highlights to figure its claws, tongue and sex, over an iron- and manganese-rich black background is a heraldic representation for Brabant (sable a lion rampant Or langued and armed gules). A smaller shield is painted in the central area of the quarter (III) (inescutcheon). Despite its very small dimensions on both instruments, it appears to be divided vertically in two halves. The left (dexter) side shows a black silhouette on a gold background, and is in accordance with the heraldic representation of Flanders (Or a lion rampant sable armed and langued gules). The lead-and silver-containing white right (sinister) side, with traces of red paints, is in accordance with the heraldic representation for Tyrol (argent an eagle displayed gules, armed, beaked, and langued Or).

Last, but not least, it is now possible to suggest a first reading of the field (IV), covering the whole right (sinister) half of the shield, which had stayed undeciphered and overlooked in previous works, from our study of the materiality of the painting. According to the XRF elemental scans, the area was painted with a smalt-containing paint which colour was initially blue (Fig. 2). Indeed, this cobalt-containing pigment seems well-adapted to represent a blue (Azure) field in heraldic arms, since "smalt provided the desirable color of natural ultramarine at a fraction of the cost" and "artists were using it [from the first half of the 16th-century on] as a substitute for ultramarine due to its similar color", which may be described as "deep blue" [24]. The XRF analyses also reveal the presence of residual gold paint in selected areas (Fig. 2). Microscopic observations reveal that this gold-flakes paint is above the smalt-containing layer, and was thus more exposed to wear. Interestingly, the elemental scan showing the distribution of copper on the tenor shield, gives clues to a fleur-de-lis silhouette in the bottom part of field (IV) (Fig. 7c), in a location compatible with the traces of gold detected in this area (Fig. 7b). A reasonable hypothesis would be that three fleur-de-lis (two at the same height, and one centered below) were painted in this originally blue field (IV), in accordance with the heraldic representation for France (Azure, three fleurs-delys Or).

To our knowledge, these results univocally point to the heraldic representation of the coat of arms of Elisabeth of Valois (1545-1568) when she was Queen of Spain, as the third spouse of Philip II of Spain (she was then also known as Isabel of Valois or Isabel de la Paz). Her own arms, those of the French Royal family on the right side, are adjoined to those of her husband Philip II, on the left side. Occasionally, such a heraldic design could also refer to the married couple, and not only to the Queen.

Elisabeth married Philip II of Spain in 1559, and was his spouse until her death, on October 3rd, 1568. This heraldic representation thus points specifically to this nine-year period. It is interesting to note that, all along this period of time, Elisabeth counted in her own House six violin players, the first "violins band" ever constituted in Spain [28]. Incidentally, the instruments themselves being obviously made before they were decorated, this work provides a terminus ante quem dating for the making of the instruments themselves, made at the latest in 1568.
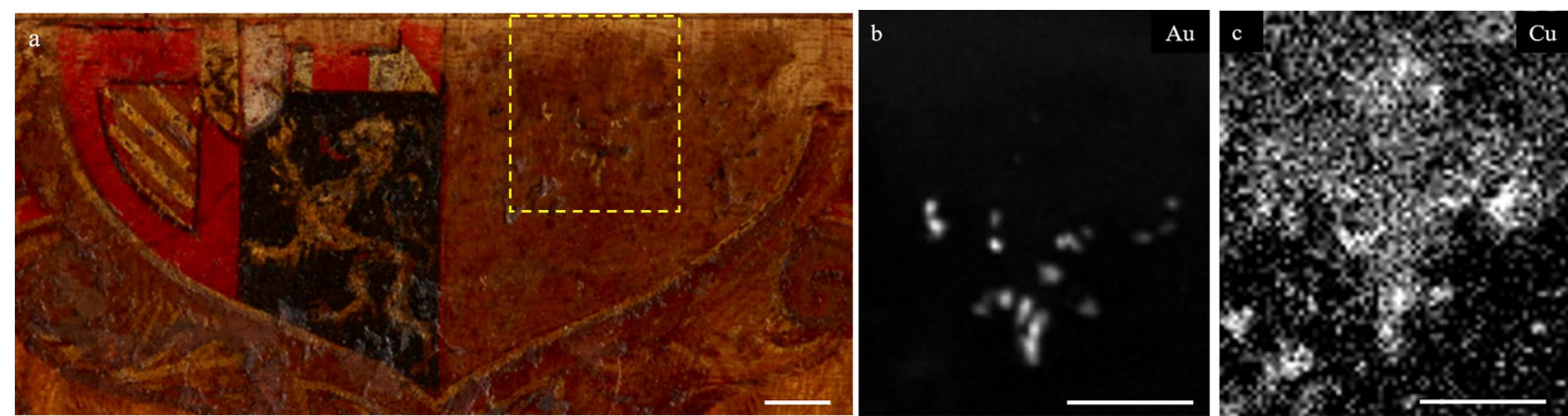

Fig. 7 a Photograph of the lower part of the coat of arms of the tenor, the dashed yellow rectangle representing the localization of the XRF elemental scans in (b) and (c) showing in white scale the distribution of Au-La and Cu-Ka, respectively (scale bars: $5 \mathrm{~mm}$ ) 


\section{Conclusion}

The coat of arms painted on two musical instruments, belonging to the same set, were illegible for different causes. The one on the tenor is mainly missing about a third of its surface due to the removal of a large part of the painted wood, and the colour of one of the fields was not corresponding to any of the heraldic tinctures. The one on the violin is so heavily abraded that almost no coloured material seems to be remaining on the wood.

Our approach, based on a combination of elemental imaging (by X-ray fluorescence spectroscopy scanning) and geometrical reconstruction, allowed revealing these painted signs and thus deducing their meaning. Notably, by detecting, identifying and localizing pigments that had discoloured (blue pigment smalt) or thought to be absent because no colour could be seen (present at the level of traces in fact), this approach led to the retrieval of the initial colours and designs of the painted coat of arms. The unique coat of arms borne by the two instruments pointed to a very specific period of time in the cultural context of the two major Catholic Royal families in 16th-century Europe.

This highlights the potentials of such an approach to enhance the informative value of historical sources often underestimated because of their lack of readability.

\section{Supplementary information}

Supplementary information accompanies this paper at https://doi. org/10.1186/s40494-020-00460-6.

Additional file 1: Figures and Tables.

\section{Acknowledgements}

The authors are grateful to Bernard Sabatier and Martin Lory, the owners of the violin, for providing access to this instrument, and to Barbara $\mathrm{H}$. Berrie for her thoughtful advice and discussions. Figure 6b,c were adapted and contain material from works by User: Heralder/Wikimedia Commons/CC-BY-SA-3.0.

\section{Authors' contributions}

MR Conceptualization, Methodology, Investigation, Resources, Writing-Original Draft, Vizualisation, Supervision. JPE Conceptualization, Methodology, Investigation, Resources, Writing-Original Draft, Vizualisation, Supervision. MO Methodology, Validation, Formal analysis, Investigation, Writing-Review and Editing. HdlC Investigation, Writing-Review and Editing. OB Investigation, Resources, Writing-Review and Editing. All authors read and approved the final manuscript.

\section{Funding}

This study was performed under the scope of a project funded by the Fondation des Sciences du Patrimoine-EquipEx PATRIMEX (ANR-11-EQPX-0034). The acquisition of the $X$-ray fluorescence scanner was supported by a grant from the lle-de-France Region-DIM "Matériaux anciens et patrimoniaux".

\section{Availability of data and materials}

The datasets analysed during the current study are available from the corresponding author on reasonable request.

\section{Competing interests}

The authors declare that they have no competing interests.

\section{Author details}

${ }^{1}$ Centre de Recherche sur la Conservation, CNRS-USR3224, Muséum National d'Histoire Naturelle, Ministère de la Culture, 36 rue Geoffroy Saint-Hilaire, Paris 75005, France. ${ }^{2}$ Équipe Conservation Recherche, Musée de la Musique, Cité de la Musique - Philharmonie de Paris, 221 Avenue Jean Jaurès, Paris 75019, France.

Received: 23 July 2020 Accepted: 1 November 2020

Published online: 11 November 2020

\section{References}

1. Cacciatori F, editor. Andrea Amati Opera Omnia - Les Violons du Roi, Ente Triennale Internazionale degli Strumenti as Arco. Consorzio Liutai Antonio Stradivari Cremona, Cremona; 2007.

2. de La Borde JB. Essai sur la musique ancienne \& moderne. T. 1, Pierres, Paris; 1780. p. 358

3. Dipper A. The King cello and the painted decorations on the Amati instruments made for the Court of Charles IX of France, 1560-1574. J Violin Soc Am, VSA papers.2006;20:15-78.

4. Tanzi M. Cremonese painting in the sixteenth century and the instruments of Andrea Amati. In: Cacciatori F, editor. Andrea Amati Opera Omnia - Les Violons du Roi, Ente Triennale Internazionale degli Strumenti as Arco. Consorzio Liutai Antonio Stradivari Cremona: Cremona; 2007. p. 41-62.

5. Witten LC. The Surviving Instruments of Andrea Amati. Early Music. 1982:10:487-94.

6. La Meucci R. naissance du violon \& les instruments de Andréa Amati. In: Lainé F, editor. Le violon italien - Une seconde voix humaine. Opéra de Dijon - Aparté: Dijon; 2012. p. 12-27.

7. Houssay A. Catalogue entry: violetta (?). In: Bongrain A, Coudroy-Saghai MH, Houssay A, Lainé F, Martin ML, editors. Altos (exhibition catalogue). Cité de la musique, Paris; 2002. p. 77.

8. Cacciatori F. Andrea Amati, magister of kings, princes and queens. In: Cacciatori F, editor. Andrea Amati Opera Omnia - Les Violons du Roi, Ente Triennale Internazionale degli Strumenti as Arco. Consorzio Liutai Antonio Stradivari Cremona: Cremona; 2007. p. 71-88.

9. Meucci R. The instruments of Andrea Amati bearing the motto "Quo unico propugnaculo..." for Marguerite de France (1553-1615). In: Cacciatori F, editor. Andrea Amati Opera Omnia - Les Violons du Roi, Ente Triennale Internazionale degli Strumenti as Arco. Consorzio Liutai Antonio Stradivari Cremona, Cremona; 2007. p. 25-39.

10. Houssay A. Cordes filées et violons en Italie au XVII ${ }^{e}$ siècle: Quelques cas d'instruments crémonais recoupés. In: Duron J, Gétreau F, editors. L'orchestre à cordes sous Louis XIV: instruments, répertoires, singularités. Librairie Philosophique J. Vrin, Paris; 2015. p. 139-162.

11. Alfeld M, Janssens K, Dik J, de Nolf W, van der Snickt G. Optimization of mobile scanning macro-XRF systems for the in situ investigation of historical paintings. J Anal Spectrom. 2011;26:899-909. https://doi.org/10.1039/ COJA00257G

12. Ravaud E, Pichon L, Laval E, Gonzalez V, Eveno M, Calligaro T. Development of a versatile XRF scanner for the elemental imaging of paintworks. Appl Phys A. 2016;122:17. https://doi.org/10.1007/s00339-015-9522-4.

13. Alfeld M, de Nolf W, Cagno S, Appel K, Peter Siddons D, Kuczewski A, Janssens K, Dik J, Trentelman K, Walton M, Sartorius A. Revealing hidden paint layers in oil paintings by means of scanning macro-XRF: a mock-up study based on Rembrandt's "An old man in military costume". J Anal At Spectrom. 2013;28:40-51. https://doi.org/10.1039/C2JA30119A.

14. Alfeld M, Mulliez M, Devolgelaere J, de Viguerie L, Jockey P, Walter P. MA-XRF and hyperspectral reflectance imaging for visualizing traces of antique polychromy on the Frieze of the Siphnian Treasury. Microchem J. 2018;141:395-403. https://doi.org/10.1016/j.microc.2018.05.050.

15. Echard JP, Malecki, V. Un amateur de musique du XIXe siècle: Louis Édouard Besson et ses violons. Musique - Images - Instruments. 2015:15:274-293.

16. Carlson B, Chiesa C, Rosengard D. Violin - Private collection Bernard Sabatier. In: Cacciatori F, editor. Andrea Amati Opera Omnia - Les Violons du Roi, Ente Triennale Internazionale degli Strumenti as Arco. Consorzio Liutai Antonio Stradivari Cremona, Cremona; 2007. p. 226. 
17. Alfeld M, Vaz Pedroso J, van Eikema Hommes M, van der Snickt G, Tauber G, Blaas J, Haschke M, Erler K, Dik J, Janssens K. A mobile instrument for in situ scanning macro-XRF investigation of historical paintings. J Anal At Spectrom. 2013;28:760-7. https://doi.org/10.1039/C3JA30341A.

18. Gettens RJ, Feller RL, Chase WT. Vermilion and Cinnabar. In: Roy A, editor. Artists' pigments: A Handbook of Their History and Characteristics, vol. 2. National Gallery of Art, Washington D.C. and Archetype Publications, London; 1993. p. 159-182.

19. Helwig K. Iron oxide pigments. In: Berrie BH, editor. Artists' pigments: A Handbook of Their History and Characteristics, vol. 4. National Gallery of Art, Washington D.C. and Archetype Publications, London; 2007. p. 39-109.

20. Gettens RJ, Kühn H, Chase WT. Lead White. In: Roy A, editor. Artists' pigments: A Handbook of Their History and Characteristics, vol. 2. National Gallery of Art, Washington D.C. and Archetype Publications, London; 1993. p. 67-81.

21. Costa $\vee$. The deterioration of silver alloys and some aspects of their conservation. Rev Conserv. 2001;2:18-34.

22. Mercuri F, Buonora P, Cicero C, Helas P, Manzari F, Marinelli M, Paolini S, Pasqualucci A, Pinzari F, Romani M, Terrei A, Verdi O, Verona Rinati G, Zammit U, Orazi N. Metastructure of illuminations by infrared thermography. J Cult Herit. 2018;31:53-62. https://doi.org/10.1016/j.culher.2017.10.008.

23. Mühlethaler B, Thissen J. Smalt. In: Roy A, editor. Artists' pigments: A Handbook of Their History and Characteristics, vol. 2. National Gallery of Art, Washington D.C. and Archetype Publications, London; 1993. p. 113-130.

24. Berrie BH. Mining for Color: New Blues, Yellows, and Translucent Paint. Early Science Med. 2015;20:308-34. https://doi.org/10.1163/1573382302046 p02.

25. Spring M, Higgitt C, Saunders D. Investigation of Pigment-Medium Interaction Processes in Oil Paint Containing Degraded Smalt. Natl Gall Tech Bull. 2005;26:56-70. https://www.jstor.org/stable/42616313.

26. Robinet L, Spring M, Pagès-Camagna S, Vantelon D, Trcera N. Investigation of the Discoloration of Smalt Pigment in Historic Paintings by Micro-X-ray Absorption Spectroscopy at the Co K-edge. Anal Chem. 2011;83:5145-52. https://doi.org/10.1021/ac200184f.

27. Echard JP. In situ multi-element analyses by energy-dispersive X-ray fluorescence on varnishes of historical violins. Spectrochim Acta B. 2004;59:1663-7. https://doi.org/10.1016/j.sab.2004.05.026.

28. Robledo Estaire L. La música en la casa de la Reina, Príncipe e Infantas. In: Robledo Estaire L, Knighton T, Bordas Ibáñez C, Carreras JJ, editors. Aspectos de la cultura musical en la corte de Felipe II. Fundación Caja Madrid: Madrid; 2000. p. 195-212.

\section{Publisher's Note}

Springer Nature remains neutral with regard to jurisdictional claims in published maps and institutional affiliations.

\section{Submit your manuscript to a SpringerOpen ${ }^{\odot}$ journal and benefit from:}

- Convenient online submission

- Rigorous peer review

- Open access: articles freely available online

- High visibility within the field

- Retaining the copyright to your article

Submit your next manuscript at $\boldsymbol{\nabla}$ springeropen.com 